\title{
SIV-Mediated Synaptic Dysfunction Is Associated with an Increase in Synapsin Site 1 Phosphorylation and Impaired PP2A Activity
}

\author{
Masoud Shekarabi, Jake A. Robinson, Mandy D. Smith, and Tricia H. Burdo \\ Department of Neuroscience, Comprehensive NeuroAIDS Center, Lewis Katz School of Medicine at Temple University, Philadelphia, Pennsylvania 19140
}

\begin{abstract}
Although the reduction of viral loads in people with HIV undergoing combination antiretroviral therapy has mitigated AIDS-related symptoms, the prevalence of neurological impairments has remained unchanged. HIV-associated CNS dysfunction includes impairments in memory, attention, memory processing, and retrieval. Here, we show a significant site-specific increase in the phosphorylation of Syn I serine 9, site 1, in the frontal cortex lysates and synaptosome preparations of male rhesus macaques infected with simian immunodeficiency virus (SIV) but not in uninfected or SIV-infected antiretroviral therapy animals. Furthermore, we found that a lower protein phosphatase 2A (PP2A) activity, a phosphatase responsible for Syn I (S9) dephosphorylation, is primarily associated with the higher S9 phosphorylation in the frontal cortex of SIV-infected macaques. Comparison of brain sections confirmed higher Syn I (S9) in the frontal cortex and greater coexpression of Syn I and PP2A A subunit, which was observed as perinuclear aggregates in the somata of the frontal cortex of SIV-infected macaques. Synaptosomes from SIV-infected animals were physiologically tested using a synaptic vesicle endocytosis assay and FM4-64 dye showing a significantly higher baseline depolarization levels in synaptosomes of SIV $^{+}$. infected than uninfected control or antiretroviral therapy animals. A PP2A-activating FDA-approved drug, FTY720, decreased the higher synaptosome depolarization in SIV-infected animals. Our results suggest that an impaired distribution and lower activity of serine/ threonine phosphatases in the context of HIV infection may cause an indirect effect on the phosphorylation levels of essential proteins involving in synaptic transmission, supporting the occurrence of specific impairments in the synaptic activity during SIV infection.
\end{abstract}

Key words: HAND; HIV-1; neurocognition; simian immunodeficiency virus; synapsin I

Significance Statement

Even with antiretroviral therapy, neurocognitive deficits, including impairments in attention, memory processing, and retrieval, are still major concerns in people living with HIV. Here, we used the rhesus macaque simian immunodeficiency virus model with and without antiretroviral therapy to study the dynamics of phosphorylation of key amino acid residues of synapsin I, which critically impacts synaptic vesicle function. We found a significant increase in synapsin I phosphorylation at serine 9, which was driven by dysfunction of serine/threonine protein phosphatase $2 \mathrm{~A}$ in the nerve terminals. Our results suggest that an impaired distribution and lower activity of serine/threonine phosphatases in the context of HIV infection may cause an indirect effect on the phosphorylation levels of essential proteins involved in synaptic transmission.

\section{Introduction}

Despite successful combination antiretroviral therapy in people with HIV (PWH), the viral reservoir can persist in the brain,

Received Jan. 19, 2019; revised May 31, 2019; accepted June 22, 2019.

Author contributions: M.S., J.A.R., and T.H.B. designed research; M.S. and M.D.S. performed research; M.S., J.A.R., and T.H.B. contributed unpublished reagents/analytic tools; M.S., J.A.R., and T.H.B. analyzed data; M.S. wrote the first draft of the paper; M.S., J.A.R., M.D.S., and T.H.B. edited the paper; M.S. wrote the paper.

This work was supported by National Institutes of Health Grant R01NS082116 to T.H.B. and Comprehensive NeuroAIDS Center Pilot Grant P30MH092 1777 to M.S.

The authors declare no competing financial interests.

Correspondence should be addressed to Tricia H. Burdo at tug82705@temple.edu. leading to neuronal dysfunction and impairment of the molecular machinery required for proper neuronal excitability and communications (Haughey et al., 2001; Musante et al., 2010; Fitting et al., 2013; Gelman, 2015). There is no evidence that HIV-1 infects neurons; however, non-neuronal HIV-infected cells, such as macrophages, microglial cells, and astrocytes, release viral neurotoxic proteins that may lead to aberrant synaptodendritic pruning and neuronal injury (Eggers et al., 2017). On the other hand, HIV-mediated neuroimmune dysfunction plays a signifi-

https://doi.org/10.1523/JNEUROSCI.0178-19.2019

Copyright $\odot 2019$ the authors 
cant role in dysregulating neurotransmission and neuroplasticity in PWH. Thus, with successful suppression of viral replication by combination antiretroviral therapy (ART), neuroinflammation continues to perturb the CNS (Burdo et al., 2013). Although many studies have investigated HIV-associated neuronal dysfunction, the molecular pathways leading to the impairment of synaptic connectivity and neuronal transmission by HIV are understudied.

Calcium-dependent synaptic vesicles (SVs) release in the "active zone" of presynaptic terminals is responsible for tuned neuronal activities in both inhibitory and excitatory synapses, governing the synaptic plasticity, learning, and memory formation (Südhof, 2012). Neurotransmission machinery consists of $\mathrm{SV}$-associated proteins that regulate neurotransmitter uptake, vesicles release, and recycling to ensure the efficient transfer of signals to the postsynaptic terminals (Greengard et al., 1993). Among SV-associated proteins is the small family of phosphoproteins called synapsins (Syn), which play a pivotal role in timely release of the neurotransmitters and neuronal differentiation (Bähler et al., 1990). Syn I undergoes multiple phosphorylation and dephosphorylation cycles at several amino acids during neurotransmission modulating the interactions with Syn I, actin, SVs, and phospholipids, thus allowing the SVs reorganization and trafficking at the synaptic terminals. The phosphorylation cycling confers tight regulation of SV trafficking within the presynaptic terminals, maintaining a releasable pool and ultimately facilitating SV fusion to the presynaptic terminals (Cesca et al., 2010).

Syn I interacts with the presynaptic components through its conserved domains. Multiple kinases, including protein kinase A (PKA), $\mathrm{Ca}^{2+} /$ calmodulin-dependent kinase (CaMK) I/II/IV, mitogen-activated protein kinase (MAPK), and cell division protein kinase 1 and 5 (cdk1/5) are known to specifically phosphorylate amino acid residues of Syn I domains, altering the Syn I interaction with synaptic components following the depolarization of neurons, thus promoting the timely trafficking of SVs for membrane fusion and neurotransmitter release to the synaptic clefts. (Onofri et al., 1997; Hosaka and Südhof, 1999; Cheetham et al., 2001; Angers et al., 2002; Yamada et al., 2009).

Various mutations in synapsins are associated with neurological disorders. Nonsense and missense mutations and single nucleotide polymorphisms have been reported in patients with epileptic seizures and autism (Fassio et al., 2011; Lignani et al., 2013), schizophrenia (Saviouk et al., 2007), bipolar disorder (Lachman et al., 2006), and multiple sclerosis (Liguori et al., 2004). Dysregulation of SUMOylation and phosphorylation of Syn I occurs in patients with autism and Huntington's diseases (Xu et al., 2013; Tang et al., 2015).

Here, we examined the state of synapsin I phosphorylation in the frontal cortex of an accelerated simian immunodeficiency virus (SIV)-infected rhesus macaque model of NeuroHIV. We found that Syn I (S9, site 1) phosphorylation is significantly higher in the frontal cortex of SIV-infected rhesus macaques compared with uninfected controls. Interestingly, we found restoration of Syn I (S9) phosphorylation in SIV-infected ARTtreated animals to the baseline levels of uninfected animals. We further demonstrated a reduction in the synaptosomal expression of protein phosphatase 2A (PP2A) A subunit in SIV-infected animals. Together with an impaired cellular distribution and lower PP2A activity in the frontal cortex of SIV-infected animals, we propose that an impaired PP2A activity in the context of SIV infection leads to the functional dysregulation of PP2A substrates at the synaptic levels. Using an endocytosis assay of synaptosomes isolated from SIV-infected macaques, we showed that an FDAapproved drug can mitigate high levels of the depolarization in synaptosomes from SIV-infected animals.

\section{Materials and Methods}

Animals. Male Indian rhesus macaques (Macaca mulatta) were inoculated intravenously with SIVmac251 viral swarm (5 ng p27; Tulane National Primate Research Center's Viral Core) and subsequently CD8depleted through administration of $10 \mathrm{mg} / \mathrm{kg}$ of anti-CD8 antibody subcutaneously at $6 \mathrm{~d}$ postinfection (dpi) and $5 \mathrm{mg} / \mathrm{kg}$ of antibody intravenously at 8 and 12 dpi (Nonhuman Primate Reagent Resource) (Lakritz et al., 2015). The $\mathrm{SIV}^{+}$animals were necropsied according to humane endpoints consistent with the recommendations of the American Veterinary Medical Association Guidelines for the Euthanasia of Animals. The development of simian AIDS was determined postmortem by the presence of Pneumocystis carinii-associated interstitial pneumonia, Mycobacterium avium-associated granulomatous enteritis, hepatitis, lymphadenitis, and/or adenovirus infection of surface enterocytes in both small and large intestines. For ART treatments, animals were not only SIV-infected and CD8-depleted but also received a triple ART regimen of Raltegravir (22 mg/kg oral twice daily, Merck), Tenofovir (30 $\mathrm{mg} / \mathrm{kg}$ subcutaneous once daily, Gilead), and Emtricitabine $(10 \mathrm{mg} / \mathrm{kg}$ subcutaneous once daily, Gilead) at 21 dpi until the timed necropsied at 118-120 dpi. Animals were anesthetized with ketamine- $\mathrm{HCl}$ and necropsied by intravenous pentobarbital overdose. Animals used in the study were housed at the Tulane National Primate Research Center. All animals used in this study were handled in strict accordance with American Association for Accreditation of Laboratory Animal Care with the approval of the Institutional Animal Care and Use Committee of Tulane University.

Immunoblotting. Whole protein lysates were prepared using a lysis buffer containing $6 \mathrm{~m}$ urea, $0.025 \%$ SDS, $5 \mathrm{~mm} \beta$-mercaptoethanol, and mechanical homogenization. Synaptosomes were isolated from frontal cortices of uninfected, $\mathrm{SIV}^{+}$, and $\mathrm{SIV}^{+}$ART animals, using Syn-PER synaptic protein extraction reagent (Thermo Fisher Scientific) as described by the manufacturer in the presence of Halt proteinase inhibitors mix (Thermo Fisher Scientific) and phosphatase inhibitors cocktail 3 (Sigma-Aldrich). Protein assays were performed using Bradford reagent (Bio-Rad) according to the manufacturer's protocol. A total of $60 \mu \mathrm{g}$ of protein lysates or $30 \mu \mathrm{g}$ of synaptosomes per condition was analyzed on SDS-PAGE gels. The following primary antibodies were used: Cell Signaling Technology: phospho-CaMKII (1:1000, 12716S; RRID: AB_2713889), Synapsin I (1:1000, 5297S; RRID:AB_2616578), phosphoSynapsin I (S9) (1:1000, 2311S; RRID:AB_2200427), PP2A A subunit (1:1000, 2039S; RRID:AB_2713889), and PKA RI $\alpha / \beta(1: 1000,3927 S$; RRID:AB_1658217). Invitrogen: Phospho-Synapsin I (S549) (1:1000, PA1-4697; RRID:AB_2175503), phospho-Synapsin I (S603) (1:1000, PA1-4604; RRID:AB_560615), phospho-CaMKI (Thr177) (1:1000, PA538434; RRID:AB_2555035), phospho-CaMKIV (Thr196/200) (1:1000, PA5-37504; RRID:AB_2554113). R\&D Systems: Phospho-CREB (1: 1000, 702710; RRID:AB_10972977), CaMKII (1:1000, MAB7280). EMD Millipore: Phospho-Synapsin I (S62/S67) (1:1000, AB9848; RRID: AB_673006). ProteinTech: GAPDH (1:3000, 60004-1-Ig; RRID: $\left.A B \_2107436\right)$. The signals were detected using ODYSSEY CLx Imaging system (LI-COR). Protein band intensities were quantified using Image Studio Software and normalized against corresponding actin or GAPDH signals.

Immunohistochemistry. Paraffin-embedded sections $(5 \mu \mathrm{m})$ were prepared and immunolabeled using a mouse Synapsin I (Synaptic System: 1:200, 106001; RRID:AB_887805) and the PP2A A subunit (1:200) antibodies. The sections were deparaffinized by $20 \mathrm{~min}$ incubation in xylene. They were then hydrated for 2 min with serial changes in $100 \%, 90 \%$, and $75 \%$ of ethanol, each two times for $2 \mathrm{~min}$ and washed with distilled water. For heat-induced antigen unmasking, the sections were heated up at $95^{\circ} \mathrm{C}$ for $20 \mathrm{~min}$ in an antigen unmasking solution (Vector, H-3300), cooled down, and washed in DPBS (Invitrogen). The sections were then incubated in $0.25 \%$ Triton X100 in DPBS for 5 min and blocked in $0.1 \%$ Triton X-100, 10\% FBS in DPBS for $1 \mathrm{~h}$. The primary antibody mix were prepared in the blocking solution, and the sections were incubated for 
Table 1. Information about the animals used in this study ${ }^{a}$

\begin{tabular}{|c|c|c|c|c|c|c|c|c|c|c|}
\hline & $\begin{array}{l}\text { Animal } \\
\text { no. }\end{array}$ & $\begin{array}{l}\text { Infection } \\
\text { status }\end{array}$ & SIVE & $\begin{array}{l}\text { Drug } \\
\text { administration }\end{array}$ & $\begin{array}{l}\text { CD8 } \\
\text { depletion }\end{array}$ & $\begin{array}{l}\text { Viral load } \\
(\log 10)\end{array}$ & $\begin{array}{l}\text { Survival } \\
\text { (days) }\end{array}$ & Species & Sex & Age (yr) \\
\hline \multirow[t]{4}{*}{ Uninfected } & A01 & $\operatorname{SIV}^{-}$ & NA & NA & NA & NA & NA & $\mathrm{RM}$ & $M$ & 3.28 \\
\hline & $\mathrm{A} 02$ & $\mathrm{SIV}^{-}$ & NA & NA & NA & NA & NA & $\mathrm{RM}$ & M & 3.41 \\
\hline & $\mathrm{A} 03$ & $\mathrm{SIV}^{-}$ & NA & NA & NA & NA & NA & RM & $M$ & 2.27 \\
\hline & A04 & $\mathrm{SIV}^{-}$ & NA & NA & NA & NA & NA & RM & $M$ & 4.1 \\
\hline \multirow[t]{5}{*}{$\mathrm{SIV}^{+}$} & A05 & $\operatorname{SIV}^{+}$ & $\mathrm{No}^{*}$ & NA & Depleted & 7.28 & 174 & RM & $M$ & 10.8 \\
\hline & A06 & $\operatorname{SIV}^{+}$ & Yes & NA & Depleted & 7.67 & 55 & RM & $M$ & 7.3 \\
\hline & A07 & $\mathrm{SIV}^{+}$ & Yes & NA & Depleted & 7.15 & 96 & RM & $M$ & 7.3 \\
\hline & A08 & $\mathrm{SIV}^{+}$ & Yes & NA & Depleted & 7.69 & 89 & RM & $M$ & 10.4 \\
\hline & A09 & $\mathrm{SIV}^{+}$ & $\mathrm{No}^{*}$ & NA & Depleted & 7.23 & 106 & $\mathrm{RM}$ & $M$ & 4.5 \\
\hline \multirow[t]{5}{*}{$\mathrm{SIV}^{+} \mathrm{ART}$} & A10 & $\mathrm{SIV}^{+}$ & No & ART & Depleted & 2.66 & 119 & RM & $M$ & 6.4 \\
\hline & A11 & $\mathrm{SIV}^{+}$ & No & ART & Depleted & 3.62 & 119 & RM & M & 10.3 \\
\hline & $\mathrm{A} 12$ & $\operatorname{SIV}^{+}$ & No & ART & Depleted & 1.6 & 120 & $\mathrm{RM}$ & $M$ & 6.2 \\
\hline & A13 & $\operatorname{SIV}^{+}$ & No & ART & Depleted & 2.66 & 118 & RM & $M$ & 6.7 \\
\hline & A14 & $\mathrm{SIV}^{+}$ & No & ART & Depleted & 2.87 & 118 & RM & $M$ & 6.1 \\
\hline
\end{tabular}

${ }^{a}$ RM, Rhesus macaque; SIVE, SIV encephalitis.

*Perivascular MФs were observed.

overnight at $4^{\circ} \mathrm{C}$. Primary antibody-treated sections were washed three times with DPBS and incubated in a mix of secondary antibodies; goat anti-rabbit Alexa-488 (1:1000, Invitrogen) and goat anti-mouse Alexa555 (1:1000, Invitrogen) for $1 \mathrm{~h}$ in the presence of DAPI to stain nuclei. The sections were imaged using a Keyence microscope at $20 \times$ or $40 \times$ objective. Corresponding images were then quantified using BZ-X Analyzer software and the Hybrid Cell Count module.

Protein kinase A assay. We assayed the PKA activity of synaptosome preparations of uninfected, $\mathrm{SIV}^{+}$, and $\mathrm{SIV}^{+}$ART rhesus macaques using PKA colorimetric activity kit (Invitrogen) according to the manufacturer's instructions in $15 \mathrm{ng}$ of final protein concentrations. The synaptosomes were prepared as previously described in the presence of phosphatase and proteinase inhibitors.

PP2A activity assay. PP2A activity was assayed in synaptosome preparations of uninfected, SIV-infected, and SIV-infected with ART rhesus macaques; $100 \mu \mathrm{g}$ of the synaptosomal proteins (without phosphatase inhibitors) were subjected to immunoprecipitation of PP2A using an antibody against PP2A A subunit (1:50, Cell Signaling Technology) in the immunoprecipitation buffer (50 mм Tris, $\mathrm{pH} 7.4,1 \% \mathrm{NP}-40,150 \mathrm{~mm}$ $\mathrm{NaCl}, 2$ mm EDTA) plus proteinase inhibitors. The complex was then pulled down using protein A Sepharose 4B (Invitrogen) and washed three times with the immunoprecipitation buffer. The PP2A assay was performed as described previously (McAvoy and Nairn, 2010) in colorimetric assay buffer (20 mM Tris, $\mathrm{pH} 7.5,5 \mathrm{~mm} \mathrm{MgCl}_{2}, 1 \mathrm{~mm}$ EGTA, $0.02 \% \beta$-mercaptoethanol, and $0.1 \mathrm{mg} / \mathrm{ml} \mathrm{BSA}$ ) using 4-nitrophenyl phosphate (pNPP, Sigma-Aldrich) as a substrate. The absorbance was read at $405 \mathrm{~nm}$ using Epoch2 microplate reader (BioTek). The protein phosphatase inhibitor fostriecin (Cayman Chemical) was added to some wells at $1 \mu \mathrm{M}$ to specifically inhibit PP2A (Swingle et al., 2007).

$\mathrm{SV}$ endocytosis assay. Pellets containing synaptosomes were analyzed for SV endocytosis assay as described previously (Daniel et al., 2012). In summary, the pellets were resuspended into SET buffer $(0.32 \mathrm{M}$ sucrose, $1 \mathrm{~mm}$ EDTA, $5 \mathrm{~mm}$ Tris, pH 7.4). Synaptosomes $(20 \mu \mathrm{g} / \mathrm{ml})$ were then attached to polyethyleneimine-coated glass bottom 96 -well microplates (Greiner bio-one) at $4^{\circ} \mathrm{C}$, as described previously (Daniel et al., 2012). Synaptosomes were revived at $30^{\circ} \mathrm{C}$ for $15 \mathrm{~min}$. In some experiments, synaptosomes were labeled with $1 \mu \mathrm{M}$ calcein blue-AM (Invitrogen) for $30 \mathrm{~min}$ at $30^{\circ} \mathrm{C}$ in $\mathrm{HBK}$ buffer $\left(143 \mathrm{~mm} \mathrm{NaCl}, 4.7 \mathrm{~mm} \mathrm{KCl}, 1.3 \mathrm{~mm} \mathrm{MgSO}_{4}\right.$ $1.2 \mathrm{mM} \mathrm{CaCl}_{2}, 20 \mathrm{~mm}$ HEPES, $0.1 \mathrm{~mm} \mathrm{NaH}_{2} \mathrm{PO}_{4}$, and $10 \mathrm{~mm}$ D-glucose, $\mathrm{pH}$ 7.4). SV endocytosis was assayed using FM4-64FX (Invitrogen) at 1 mM. Extraneous FM4-64FX was then washed with 1 mu Advasep-7 (Biotium) for $2 \mathrm{~min}$. Hydroxy dynasore was added at $100 \mu \mathrm{M}$ to some wells for $30 \mathrm{~min}$ before FM4-64FX labeling. For stimulation, synaptosomes were depolarized in the presence $40 \mathrm{~mm} \mathrm{KCl}$ for $2 \mathrm{~min}$ at $30^{\circ} \mathrm{C}$. The plates were either immediately imaged or fixed using $4 \%$ PFA in HBK buffer. The imaging was performed using a Keyence microscope at $20 \times$ or $40 \times$ objective. Four images per well from three wells were captured using the same exposure times. Total fluorescence intensities of objects between 3 and $75 \mu \mathrm{m}$ in area were measured and compared.

Statistical analysis. The data analysis comparing the intensities between the samples were performed either with one-way ANOVA with post hoc Tukey HSD (honest significant difference) or with Student's $t$ test. A criterion of $\alpha=0.05$ was used to establish statistical significance. The mean values \pm SEM were results of analysis with the indicated number $(n)$ of experiments.

\section{Results}

\section{Synapsin I is hyperphosphorylated at site 1 serine 9 in the frontal cortex of $\mathrm{SIV}^{+}$rhesus macaques}

To investigate mechanisms of SIV-associated CNS dysfunction, 10 male Indian rhesus macaques were intravenously infected with SIVmac251 followed by depletion of CD8 ${ }^{+}$cells by antiCD8 antibody to accelerate SIV CNS pathology $\left(\mathrm{SIV}^{+}\right)$(Lakritz et al., 2015). Five SIV-infected rhesus macaques received a triple ART regimen at 21 dpi to suppress the viral load $\left(\mathrm{SIV}^{+} \mathrm{ART}\right)$. $\mathrm{SIV}^{+}$animals (A05-A09) were necropsied according to humane endpoints consistent with the recommendations of the American Veterinary Medical Association Guidelines for the Euthanasia of Animals, and SIV ${ }^{+}$ART animals (A10-A14) were time-sacrificed at 120 dpi. Four uninfected rhesus macaques (A01-A04) served as experimental controls (Table 1). We prepared brain lysates from the frontal cortex of uninfected, $\mathrm{SIV}^{+}$, and SIV ${ }^{+}$ART animals and examined Syn I phosphorylation at several phosphorylation sites using Syn I phosphor-specific antibodies. The phosphorylation of Syn I (S9) was significantly different among uninfected, $\mathrm{SIV}^{+}$, and $\mathrm{SIV}^{+}$ART animals (Fig. $1 A, B$, top; one-way ANOVA, $\left.F_{(2,11)}=6.3849, p=0.01\right)$. Syn I (S9) phosphorylation was significantly higher in $\mathrm{SIV}^{+}$cohort compared with uninfected animals (Fig. $1 B$; $p<0.05$ ). Furthermore, Syn I (S9) phosphorylation was lower in $\mathrm{SIV}^{+}$ART animals compared with $\mathrm{SIV}^{+}$ animals, suggesting that ART mitigated SIV-associated increased phosphorylation (Fig. $1 B$; $p<0.05$ ). Total Syn I protein expression was not significantly different among groups indicating a higher phosphorylation at $S 9$ than an increased expression of Syn I in SIV ${ }^{+}$animals (Fig. $1 B$, bottom). Next, we examined sections of the frontal cortex of $\mathrm{SIV}^{+}$animals by immunofluorescence using anti-p-Syn I (S9) and $\beta$ III tubulin antibodies and quantified as the fluorescent intensity. Phosphorylated Syn I (S9) significantly differed among the groups (Fig. 1C,D; one-way 
A

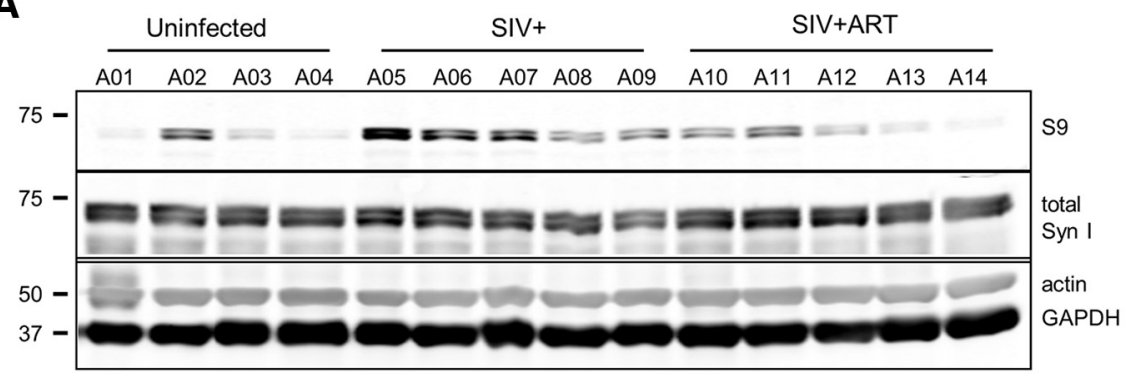

\section{C}

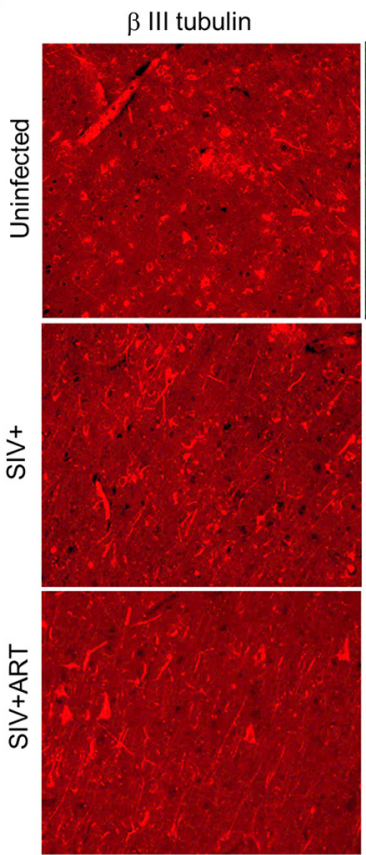

Syn I (S9)
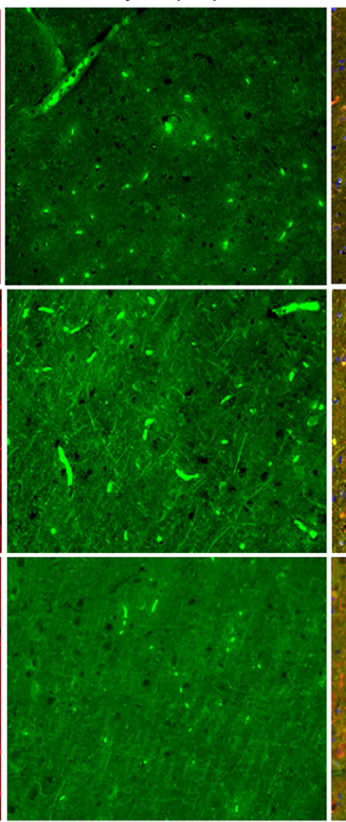

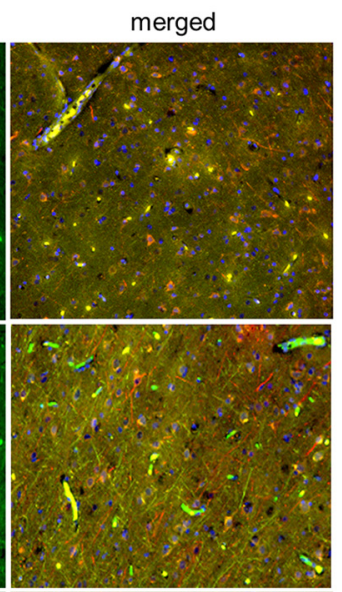

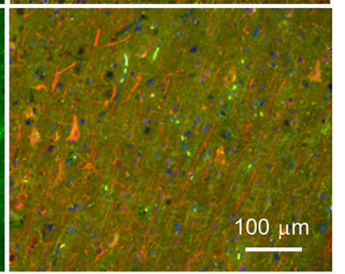

B
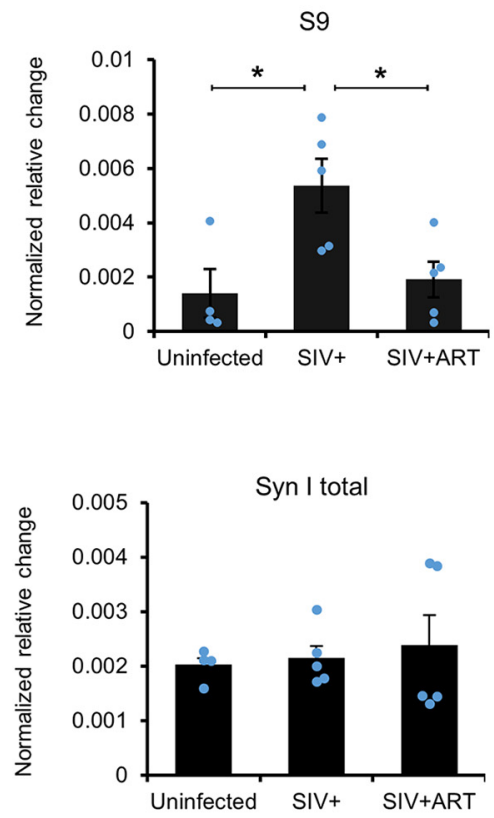

D

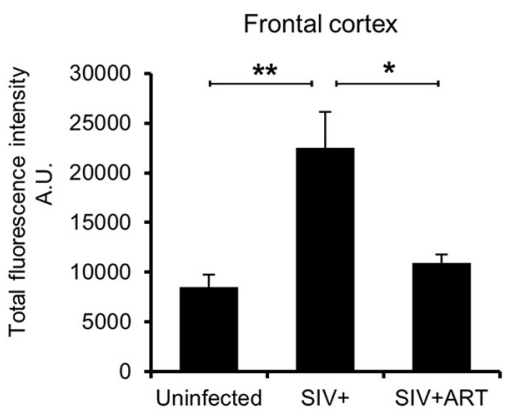

Figure 1. Hyperphosphorylation of Syn I (S9) in the frontal cortex of $\mathrm{SIV}^{+}$rhesus macaques. $A$, Representative Western blots of whole-tissue protein lysates from the frontal cortex of uninfected, $\mathrm{SIV}^{+}$, and SIV ${ }^{+}$ART animals using an antibody against Syn I (S9). B, Bands were quantified and normalized against actin or GAPDH signals. There was a significant difference among groups. A higher Syn I (S9) phosphorylation was detected in the frontal cortex lysates from SIV ${ }^{+}$compared with uninfected or SIV ${ }^{+}$ART. No changes were observed in the expression levels of total Syn I ( $\boldsymbol{B}$, bottom). C, Immunohistochemistry of sections of uninfected, SIV ${ }^{+}$, and SIV ${ }^{+}$ART probed with anti-Syn I (S9, green) and $\beta$ III tubulin (red) antibodies. D, Quantification of experiments illustrated in Crevealed a significant difference among groups. A significant increase in the intensities of the positive Syn I (S9) signals was detected. ${ }^{* *} p<0.005$ (one-way ANOVA with Tukey HSD). ${ }^{*} p<0.05$ (one-way ANOVA with Tukey HSD). Error bars indicate SD of mean; \pm SEM.

ANOVA, $\left.F_{(2,21)}=8.3541, p=0.002\right)$. These experiments further confirmed higher p-Syn I (S9) in the cortex of SIV ${ }^{+}$animals. We also examined sections of parietal and occipital lobes for p-Syn I (S9); both lobes displayed significantly higher S9 phosphorylations in $\mathrm{SIV}^{+}$compared with sections of uninfected and $\mathrm{SIV}^{+}$ ART animals (Fig. $2 A, B$; one-way ANOVA, $F_{(2,41)}=4.97, p=$ 0.01 and $F_{(2,28)}=8.87, p=0.001$, respectively).

We further assessed Syn I phosphorylation on residues located in the other Syn I domains. Phosphorylation-specific antibodies against p-Syn I (S62/67), p-Syn I (S549), and p-Syn I (S603) were used on the frontal cortex lysates of uninfected, $\mathrm{SIV}^{+}$, and $\mathrm{SIV}^{+}$ ART animals (Fig. 3). We found an overall decreasing trend in Syn I phosphorylation at p-Syn I (S62/67) (one-way ANOVA, $\left.F_{(2,11)}=3.2108, p=0.08\right)$ and no significant change in $\mathrm{p}$-Syn I (S549). Phosphorylation at Syn I (S603) residue exhibited an increasing trend with a significant higher phosphorylation in $\mathrm{SIV}^{+}$ART animals compared with uninfected lysates (Fig. 3B; one-way ANOVA, $\left.F_{(2,11)}=4.2399, p=0.04\right)$.
Phosphorylation of Syn I (S9) in synaptosomes of $\mathrm{SIV}^{+}$animals

To assess Syn I phosphorylation in preparations of the nerve terminals, we prepared synaptosomes from the frontal cortex of uninfected, $\mathrm{SIV}^{+}$, and SIV ${ }^{+}$ART animals and assessed Syn I (S9) phosphorylation by Western blots. We found significant differences among groups (one-way ANOVA, $F_{(2,12)}=14.5737, p=$ 0.0006). Significantly higher levels of Syn I (S9) phosphorylation were detected in the synaptosome preparations of frontal cortex of $\mathrm{SIV}^{+}$animals compared with synaptosomes from uninfected or $\mathrm{SIV}^{+}$ART animals (Fig. 4A,B; post hoc, $p<0.005$ ). We also found that $\mathrm{S} 62 / \mathrm{S} 67$ phosphorylations were not different among groups (Fig. 4B). A significant increase in S549 was also observed among three groups in the synaptosome preparations (Fig. $4 B$; one-way ANOVA, $\left.F_{(2,11)}=4.3469, p=0.04\right)$, with a significant increase between with $\mathrm{SIV}^{+} \mathrm{ART}$ compared with $\mathrm{SIV}^{+}$animals (Fig. 4B; post hoc, $p<0.05$ ). The phosphorylation of S603 site was not significantly different among the groups (Fig. $4 B$ ). 
A
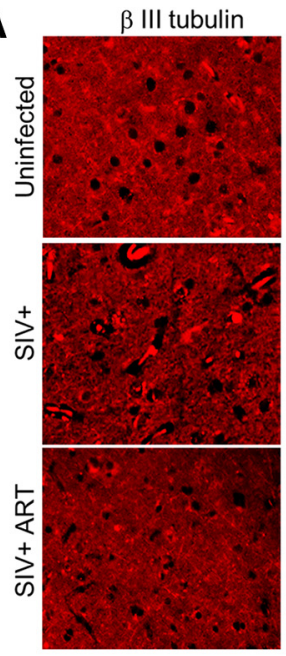

B
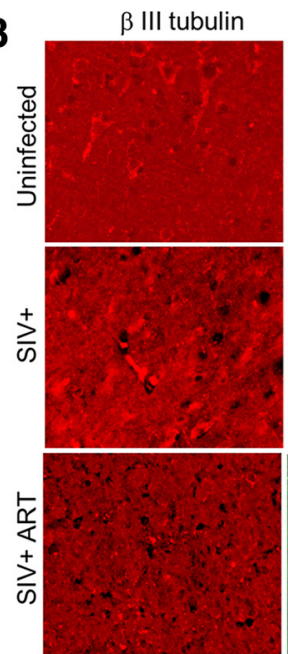

Syn I (S9)

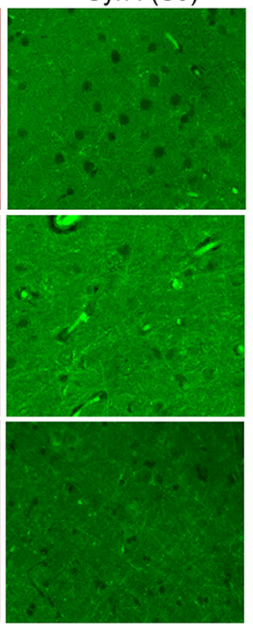

Syn I (S9)


merged

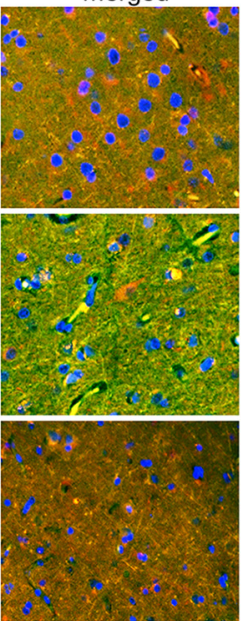

merged

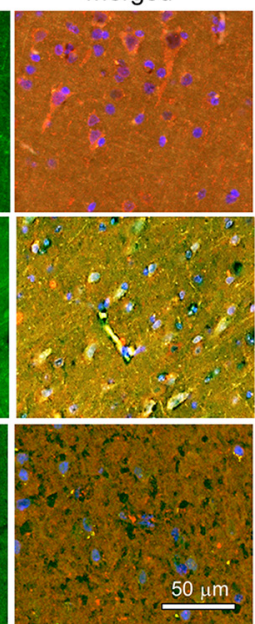



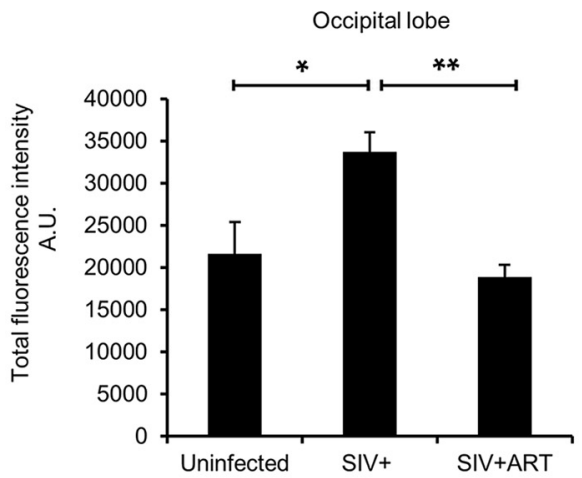

Figure 2. Hyperphosphorylation of Syn I (S9) in parietal and occipital lobes of SIV ${ }^{+}$rhesus macaques. Representative sections of parietal $(\boldsymbol{A})$ and occipital ( $\left.\boldsymbol{B}\right)$ lobes of uninfected, SIV $^{+}$, and SIV ${ }^{+}$ ART animals were immunostained with antibodies against $\beta$ III tubulin (red) and p-Syn I (S9, green). P-Syn I (S9) signal intensities were measured and quantified. Significant increases in the immunopositive p-Syn I (S9) signals were observed in SIV ${ }^{+}$sections compared with uninfected or SIV ${ }^{+}$ART sections. PL, Parietal lobe; $0 \mathrm{~L}, 0$ occipital lobe. ${ }^{*} p<0.05$ (one-way ANOVA with Tukey HSD). ${ }^{* *} p<0.005$ (one-way ANOVA with Tukey HSD). Error bars indicate SD of mean; \pm SEM.

We hypothesized that the higher levels of phosphorylated Syn $\mathrm{I}(\mathrm{S} 9)$ in $\mathrm{SIV}^{+}$animals may indicate either a dysregulation of PKA and/or CaMK I/IV kinases responsible for S9 phosphorylation or a lower activity of PP2A, which is responsible for Syn I (S9) dephosphorylation. To verify the pathway(s) responsible for a higher Syn I (S9) phosphorylation in $\mathrm{SIV}^{+}$animals, we examined the activities of kinases responsible for S9 phosphorylation. The PKA activity was assessed by quantifying the phosphorylated cAMP response element-binding protein (p-CREB) in the frontal cortex synaptosomes (Delghandi et al., 2005). No significant differences were observed in the overall p-CREB levels (Fig. 5A). Furthermore, the expression of PKA catalytic subunit was assessed by Western blot and the PKA activity directly assayed in SIV infected and compared with synaptosomes from uninfected or $\mathrm{SIV}^{+}$ART animals. There were no significant differences in the expression of PKA catalytic subunit or PKA activity among the groups (Fig. $5 B, C$ ).

Next, we examined the activities of both CaMKI and IV kinases known to phosphorylate Syn I (S9) (Huttner et al., 1981). An antibody against the phosphorylated CaMKIV (Tyr196/ Tyr200) and one against the phosphorylated CaMKI (Tyr177) were used to test the synaptosome preparations for the CaMKIV and CaMK I activities, respectively (Wayman et al., 2006; Yadav et al., 2009). These experiments indicated no difference in the level of active forms of phosphorylated CaMKI or IV among $\mathrm{SIV}^{+}, \mathrm{SIV}^{+}$ART, or uninfected animals (Fig. 5D,E).

In addition, we verified the CaMKII activity, which promotes the phosphorylation of Syn I (S603) (Onofri et al., 1997). We used an antibody against Thr286, which detects an active form of CaMKII. In synaptosomes, we found no significant differences among groups in the p-CaMKII levels when the loadings were normalized against GAPDH (Fig. $6 A, B$; one-way ANOVA, $F_{(2,11)}$ $=0.4002, p=0.68)$. However, when we compared the p-CaMKII levels with the total CaMKII protein, a significant difference was found among the groups (Fig. $6 \mathrm{~B}$; one-way ANOVA, $F_{(2,11)}=$ $4.7433, p=0.03)$, specifically a significant reduction of the CaMKII activity in synaptosomes of $\mathrm{SIV}^{+}$ART compared with $\mathrm{SIV}^{+}$animals (post hoc, $p<0.05$ ). In total lysates (Fig. 6C,D), the CaMKII activity was found significantly different among groups (one-way ANOVA, $F_{(2,11)}=5.3209, p=0.02$ ) with SIV ${ }^{+}$ART significantly decreased from $\mathrm{SIV}^{+}(p<0.05)$. We also found significant differences among groups when the lysates were probed with anti-CaMKII (one-way ANOVA, $F_{(2,11)}=5.6849$, $p=0.02)$ with a significant decrease in the CaMKII expression in 
A

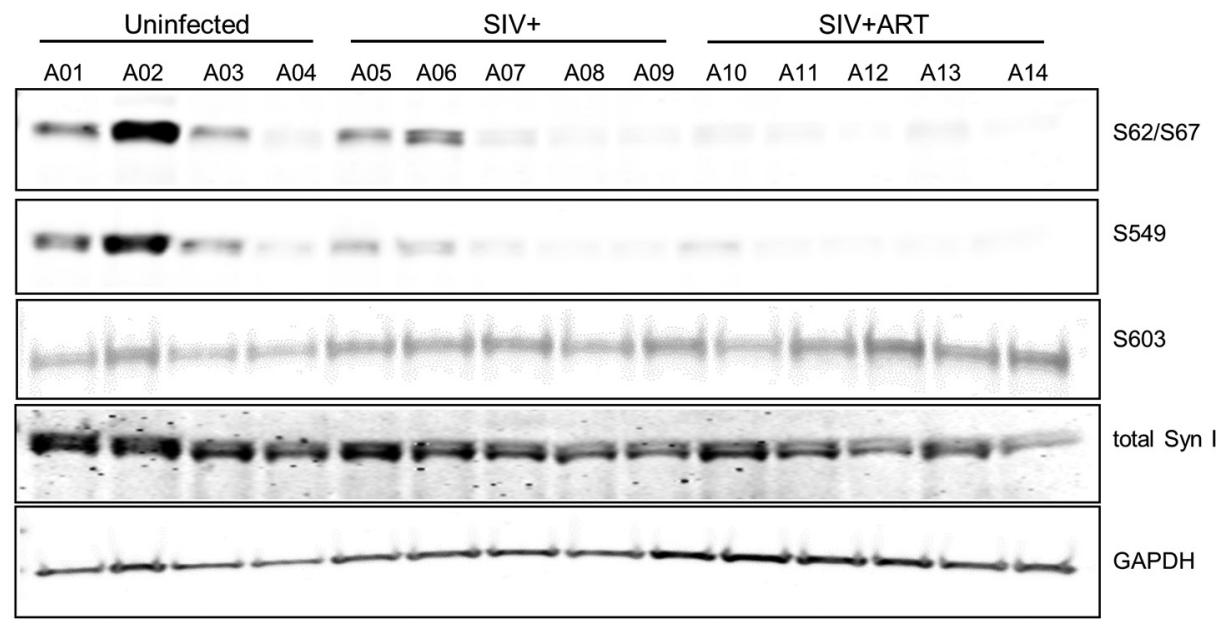

B

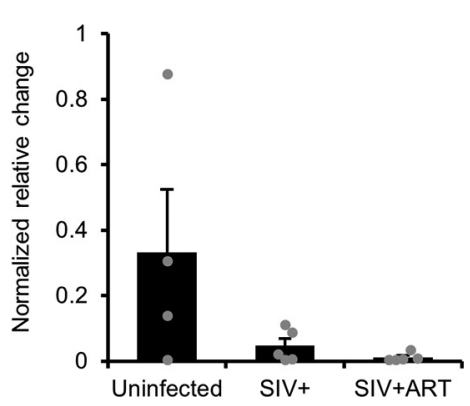

S549

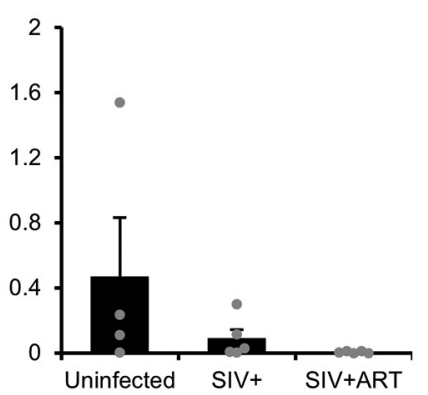

S603

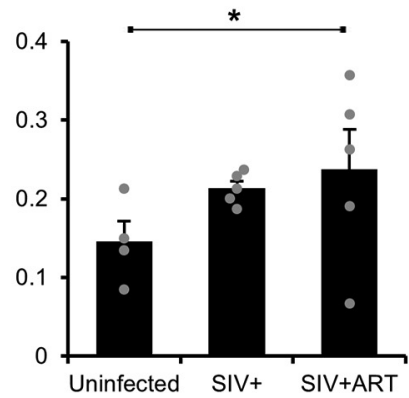

Figure 3. Effect of SIV infection on Syn I phosphorylation at S62/S67, S549, and S603 sites in the frontal cortex of rhesus macaques. A, Protein lysates of the frontal cortex from uninfected, SIV ${ }^{+}$, and SIV ${ }^{+}$ART animals were analyzed by Western blot using specific antibodies against Syn I (S62/S67, S549, and S603) sites. B, Band intensities were quantified and normalized against GAPDH and graphed as mean. No significant changes were observed among groups in the phosphorylation levels of S62/S67 and S549. However, a significant increase was detected in Syn I (S603) when frontal cortex lysates from uninfected were compared with SIV ${ }^{+}$ART animals. ${ }^{*} p<0.05$ (one-way ANOVA with Tukey HSD). Error bars indicate SD of mean; \pm SEM.

\section{A}

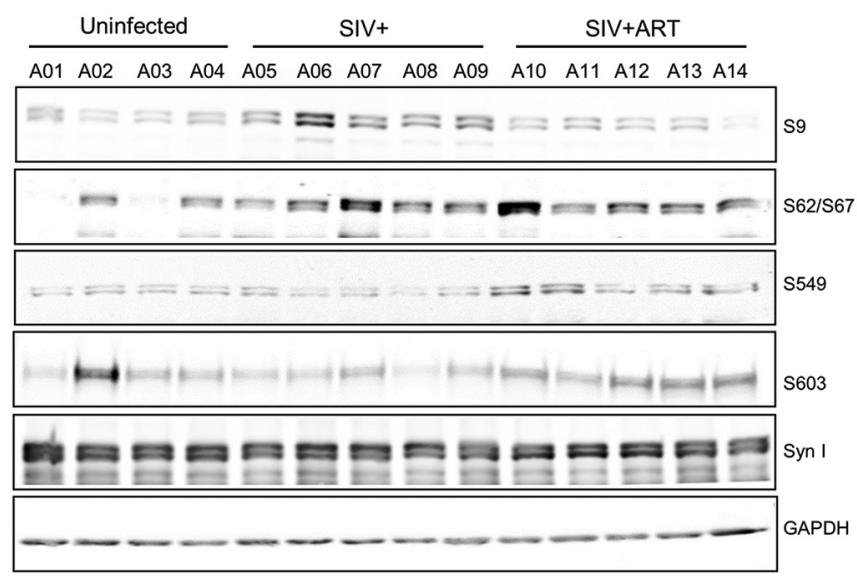

\section{B}



$562 / 67$

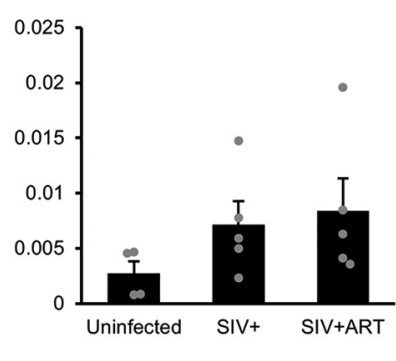

S603

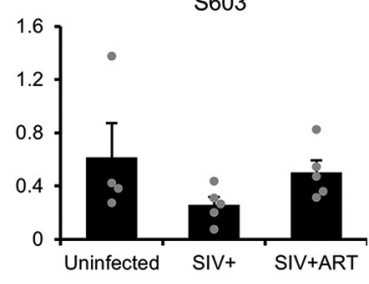

Figure 4. A significant increase in Syn I (S9) phosphorylation of synaptosome preparations from SIV ${ }^{+}$rhesus macaques. $A$, Synaptosome preparations of uninfected, SIV ${ }^{+}$, and SIV ${ }^{+}$ART were subjected to immunoblot analysis using antibodies recognizing the indicated phosphorylation sites of Syn I. Antibodies against GAPDH and total Syn I were used to assess protein loads. B, Band intensities from every sample were quantified and normalized against their corresponding GAPDH band, and means were graphed. A significant increase was observed among groups in Syn I ( 59 ) (ANOVA, $p<0.005$ ). Although no significant differences were detected among groups in $\$ 62 / 67,5549$, and $S 603$ phosphorylation, there was a significant increase in $\$ 549$ phosphorylation between synaptosomes of SIV ${ }^{+}$and SIV ${ }^{+}$ART animals. ${ }^{*} p<0.05$ (one-way ANOVA with Tukey HSD). ${ }^{* *} p<0.005$ (one-way ANOVA with Tukey HSD). Error bars indicate SD of mean; \pm SEM. 
A
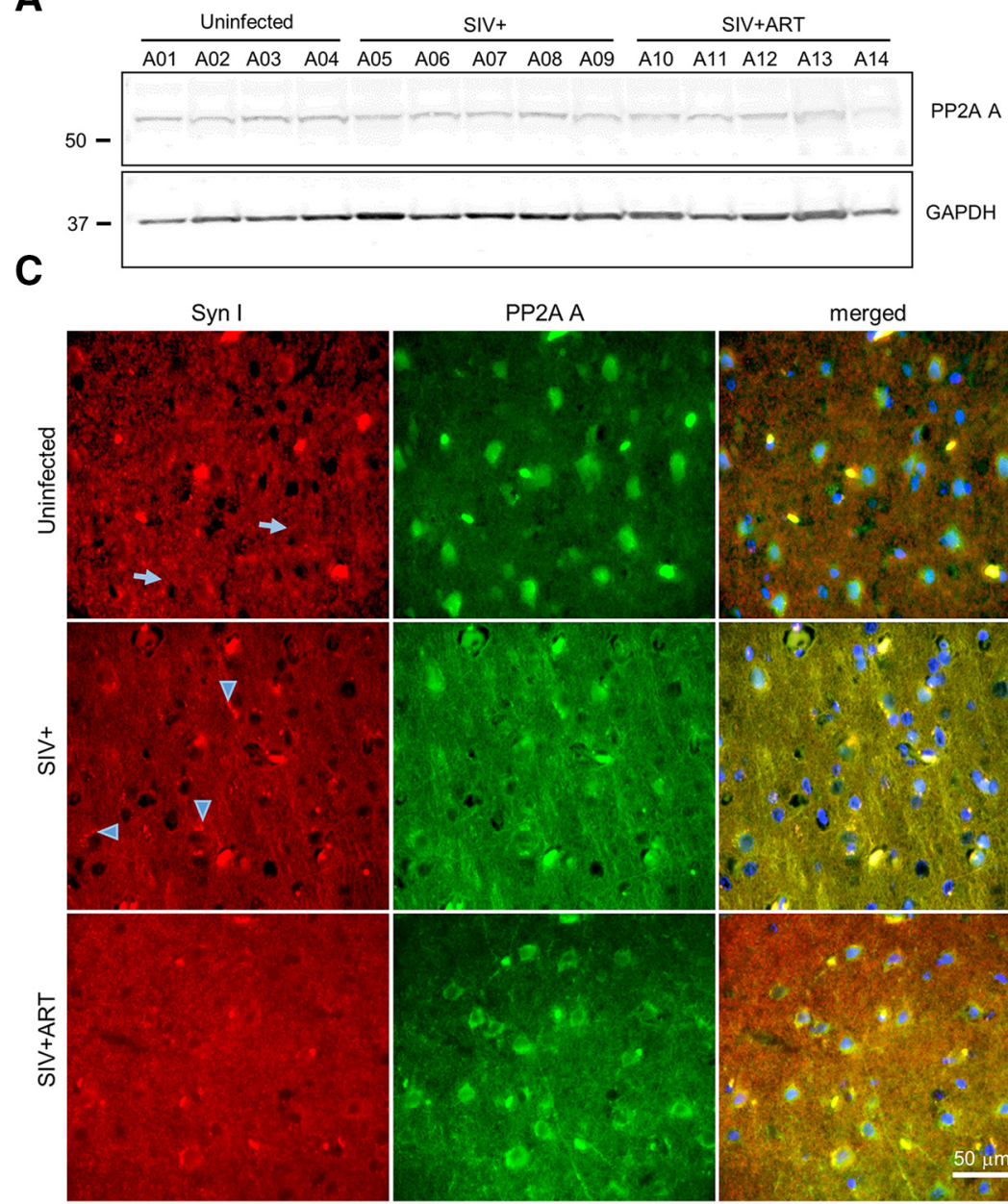
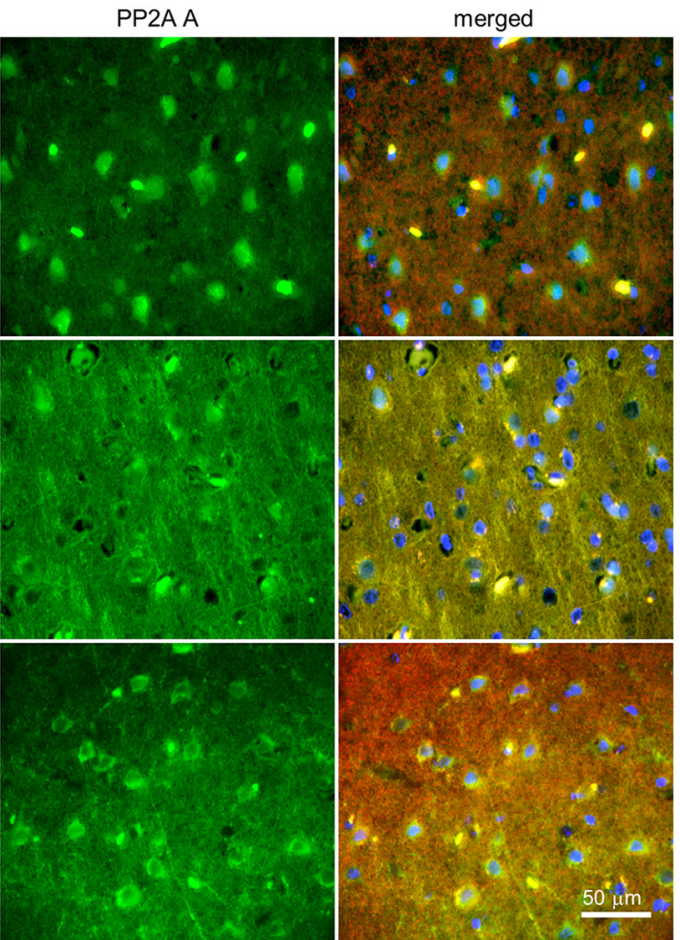

B

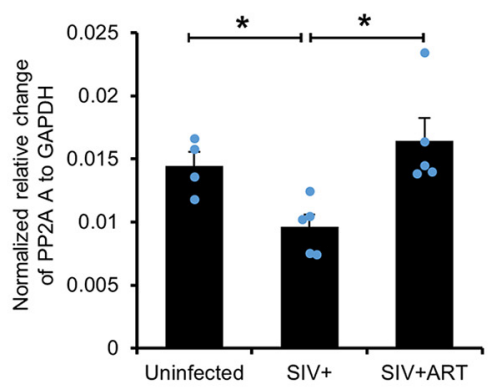

D

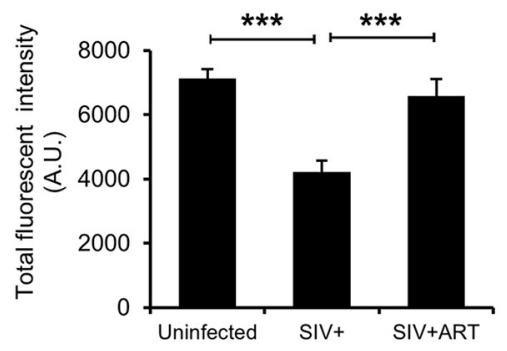

E

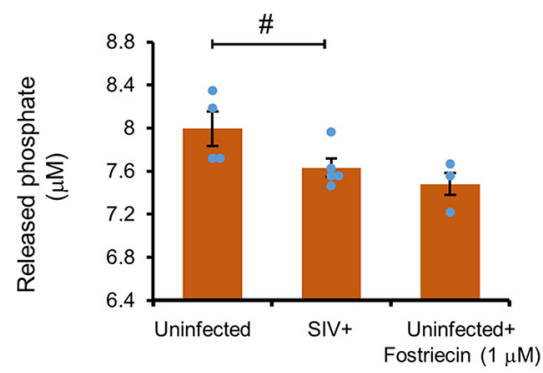

Figure 7. Impairments in the expression, cellular distribution, and activity of PP2AA subunit in SIV ${ }^{+}$frontal cortex. A, Synaptosome preparations of the frontal cortex from uninfected, SIV ${ }^{+}$, and $\mathrm{SIV}^{+}$ART animals were subjected to Western blot analysis with an antibody recognizing PP2A A subunit. The same blot was reprobed with an antibody against GAPDH to assess and quantify protein loads. $\boldsymbol{B}$, To graph the means, band densities were measured and normalized against GAPDH. There was a significant difference of PP2A A subunit expression among groups. $\boldsymbol{C}$, Representative images of the frontal cortex of uninfected, SIV ${ }^{+}$, and SIV ${ }^{+}$ART animals, which were immunoprobed with Syn I (red) and PP2A A (green), revealed lower PP2A A-positive signals in neurons somata. Neurons coexpressing Syn I and PP2A A in sections of SIV ${ }^{+}$animals exhibited accumulation of perinuclear staining (arrowhead); whereas in uninfected and SIV ${ }^{+}$ART sections, the stainings were more dispersed (arrows). D, Intensities of PP2A A signals were measured and graphed. A significant decrease was observed in the signals from SIV ${ }^{+}$sections. $\boldsymbol{E}$, Equal amounts of lysates from uninfected and SIV ${ }^{+}$animals were subjected to immunoprecipitation using PP2A A subunit antibody and phosphatase assay using pNPP as a substrate. A significant reduction of PP2A activity in synaptosomes of SIV ${ }^{+}$animals is plotted. fostriecin $(1 \mu \mathrm{M})$ specifically inhibited PP2A activity. ${ }^{*} p<0.05$ (Student's $t$ test). ${ }^{*} p<0.05$ (one-way ANOVA with Tukey HSD). ${ }^{* * *} p<0.001$ (one-way ANOVA with Tukey HSD). Error bars indicate SD of mean; \pm SEM; A.U., Fluorescence arbitrary units.

lysates from SIV ${ }^{+}$ART animals (post hoc, $p<0.05$ ) compared with $\mathrm{SIV}^{+}$animals. When the lysates were normalized with the total CaMKII protein (pCaMKII/CaMKII), a trend for a difference among groups was observed (one-way ANOVA, $F_{(2,11)}=$ 3.9723, $p=0.05$ ) (Fig. 6D).

\section{Alterations in the PP2A A subunit expression, cellular} distribution, and $\mathrm{PP} 2 \mathrm{~A}$ activity in the $\mathrm{SIV}^{+}$brain

SV trafficking at the presynaptic terminals is regulated by dephosphorylation of Syn I by PP2A and PP2B (calcineurin), which modulate SVs clustering and their associations with actin cytoskeleton (Jovanovic et al., 1996, 2001). Syn I (S9) is selectively dephosphorylated by PP2A in a tonic and $\mathrm{Ca}^{2+}$ independent fashion (Jovanovic et al., 2001). We verified the expression levels of PP2A A subunit and found significant changes among the groups (one-way ANOVA, $F_{(2,11)}=6.8413, p=0.012$ ) with a significant decrease when synaptosomes from $\mathrm{SIV}^{+}$compared with $\mathrm{SIV}^{+}$ART animals (Fig. $7 A, B$; post hoc, $p<0.05$ ). Indeed, upon examining the cellular distribution of PP2A A subunit us- ing immunolabeling of $\mathrm{SIV}^{+}$animals frontal cortex, we found that both Syn I and PP2A A subunit were coexpressed in the somata of neurons (Fig. 7C) with significantly lower PP2A A detected compared with uninfected or $\mathrm{SIV}^{+}$ART frontal cortex (Fig. $7 D$; one-way ANOVA, $F_{(2,28)}=12.9317, p=0.0001$ ). Syn I expression, predominantly as perinuclear aggregates, was found in the $\mathrm{SIV}^{+}$cortex; whereas in uninfected animals, a dispersed distribution of Syn I-positive puncta was detected (Fig. 7C, arrows vs arrowheads). Because of the lower protein levels and impaired distributions of PP2A A subunit, we measured the PP2A activity in $\mathrm{SIV}^{+}$synaptosomes by immunoprecipitating PP2A A subunit from the synaptosome preparations of uninfected and $\mathrm{SIV}^{+}$animals and assaying the activity of bound PP2A holoenzyme. We observed a significantly lower PP2A activity in synaptosomes from $\mathrm{SIV}^{+}$animals compared with uninfected animals (Fig. $7 E$; $t$ test, $p<0.05$ ). In addition, the application of fostriecin at $1 \mu \mathrm{M}$, which specifically inhibits PP2A (Swingle et al., 2007), decreased the PP2A activity in uninfected synaptosomes to that of $\mathrm{SIV}^{+}$synaptosomes. These experiments strongly suggest 
A

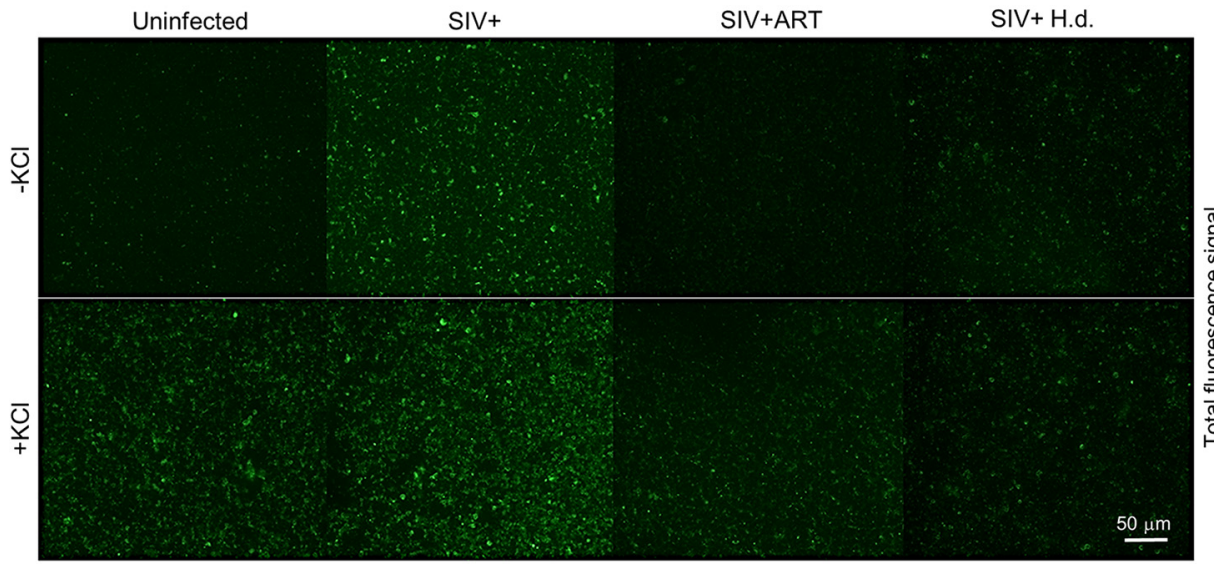

B

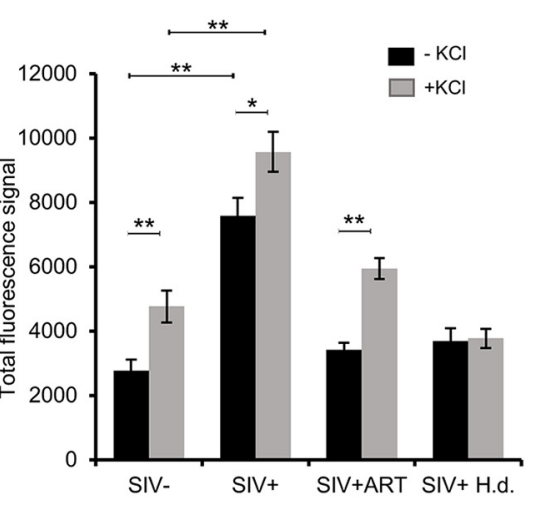

Figure 8. Endocytosis assay of SVs using synaptosomes from the frontal cortex of rhesus macaques. A, Frontal cortex synaptosomes were assayed on glass microplates in the presence of 40 mm $\mathrm{KCl}$ and FM4-64. Brighter fluorescence signals are an indication of increased SV endocytosis, and the dye and lipid interactions thus increase in depolarization of synaptosomes. Significantly higher baseline fluorescence signals were detected in synaptosomes of SIV ${ }^{+}$animals, even in the absence of KCl. Synaptosomes from SIV ${ }^{+}$animals pretreated with an inhibitor of dynamin-mediated endocytosis exhibited low signals in both the presence and absence of $\mathrm{KCl}$. B, Quantification of fluorescence signals using the total fluorescence signals recorded in different conditions are graphed. H.d., Hydroxy dynasore. ${ }^{*} p<0.05$ (one-way ANOVA with Tukey HSD). ${ }^{* *} p<0.005$ (one-way ANOVA with Tukey HSD). Error bars indicate SD of mean; \pm SEM.

that the lower activity of PP2A is responsible for the higher Syn I (S9) phosphorylation in $\mathrm{SIV}^{+}$brains.

\section{SV endocytosis assay of $\mathrm{SIV}^{+}$synaptic terminals}

To functionally test the efficacy of SVs release in the synaptic terminals of rhesus macaque brains, we used an endocytosis assay using frontal cortex synaptosomes. In the presence of $\mathrm{KCl}$, synaptosomes can undergo depolarization and induce SV exocytosis at the synapse (Coffey et al., 1993). Following depolarization, endocytosis events will recycle the released vesicles (Lou, 2018). We assayed synaptosome preparations from the frontal cortex of uninfected, $\mathrm{SIV}^{+}$, and $\mathrm{SIV}^{+}$ART animals using FM4-64 by adhering the synaptosomes onto glass microplates (Daniel et al., 2012). Synaptosomes from the frontal cortex of animals were then depolarized using $\mathrm{KCl}$ and subsequently imaged. In uninfected animals, we observed a significant increase in the fluorescence signals following $\mathrm{KCl}$ treatments indicating an active endocytosis/exocytosis in KCl-treated synaptosomes (Fig. $8 A, B$; $p<0.005)$. We found elevated fluorescence signals, even in the absence of $\mathrm{KCl}$ in synaptosomes from $\mathrm{SIV}^{+}$animals (Fig. 8A, $B$; $p<0.005)$. The fluorescence signals in synaptosomes from $\mathrm{SIV}^{+}$ ART brains had a similar increase as uninfected synaptosomes in the presence of $\mathrm{KCl}(p<0.005)$. Hydroxy dynasore inhibits dynamin-mediated SV endocytosis (Macia et al., 2006). Application of hydroxy dynasore to the synaptosomes mitigated the fluorescence signals in the presence of $\mathrm{KCl}$, thus inhibiting depolarization (Fig. 8A,B). These experiments further support the existence of more unbound SVs available for fusion at the synaptic terminals in $\mathrm{SIV}^{+}$than uninfected or $\mathrm{SIV}^{+}$ART animals, indicating a higher phosphorylation of Syn I (S9).

\section{A phosphatase-activating drug mitigated SV endocytosis/ exocytosis cycle}

PP2A plays a key role in cellular pathways and is a therapeutic target for a number of human conditions, such as multiple sclerosis, cancer, and inflammatory chronic respiratory disease (Perrotti and Neviani, 2013). To test the ability of a phosphataseactivating drug FTY720 (a sphingosine analog) to mitigate SV release from synaptosomes from $\mathrm{SIV}^{+}$, FTY720 was added to the synaptosomes in both resting and depolarizing states. FTY720 strongly lowered the fluorescence intensity in a concentrationdependent fashion, indicating slower endocytosis/exocytosis events in the presence of the phosphatase-activating drug (Fig. $9 A, B)$. The quenching effect of FTY720 was significantly slower in synaptosomes from $\mathrm{SIV}^{+}$than in synaptosomes from uninfected animals. At 10 and $50 \mu \mathrm{M}$, FTY720 exhibited stronger effect on uninfected than $\mathrm{SIV}^{+}$synaptosomes $(t$ test: $10 \mu \mathrm{M}, p<0.005$; $50 \mu \mathrm{M}, p<0.05)$. Thus, the activation of PP2A causes a slower depolarization in synaptosomes from $\mathrm{SIV}^{+}$animals because of the dephosphorylated Syn I and a greater SV in tethered state.

\section{Discussion}

The phosphorylation of synaptic proteins plays an important role in quickly modifying their functions and regulates synaptic efficacy. Among them, Syn I (S9) phosphorylation modulates Syn I association with SVs, and actin cytoskeleton thus regulates the dynamics of neurotransmitter release to the synaptic clefts. Basal levels of Syn I (S9) phosphorylation are low and highly conserved in both vertebrates and invertebrates (Hosaka and Südhof, 1999; Menegon et al., 2000, 2006; Chi et al., 2001, 2003; Bonanomi et al., 2005). Here, we investigated changes in Syn I phosphorylations in the frontal cortex of SIV-infected rhesus macaques as a model of NeuroHIV (Fig. 10). Our results revealed a specific increase in Syn I (S9) phosphorylation in $\mathrm{SIV}^{+}$but not in uninfected or $\mathrm{SIV}^{+}$animals treated with ART. Furthermore, we found a lower expression and perinuclear accumulation of PP2A A (scaffold) subunit, which may indicate an impaired cellular distribution. Interestingly, Syn I was coexpressed with these perinuclear accumulations. Therefore, both pathological events might be a secondary effect, which triggered, with the lack of available PP2A A subunit, to form an active PP2A holoenzyme at the nerve terminals. It was suggested that the A subunit is responsible for the catalytic activity of PP2A by inducing a conformational change in catalytic subunit (Zhou et al., 2003). The interaction of PP2A and viral pathways was also reported (Guergnon et al., 2011). PP2A activity reversely regulated HIV-1 transcription through LIS1, a microtubule-associated protein, which binds to PP2A and displaces its regulatory B subunit (Epie et al., 2006). However, a positive regulatory role of $\mathrm{PP} 2 \mathrm{~A}$ on $\mathrm{HIV}-1$ transcription has also been reported in which higher nonactive core en- 
A

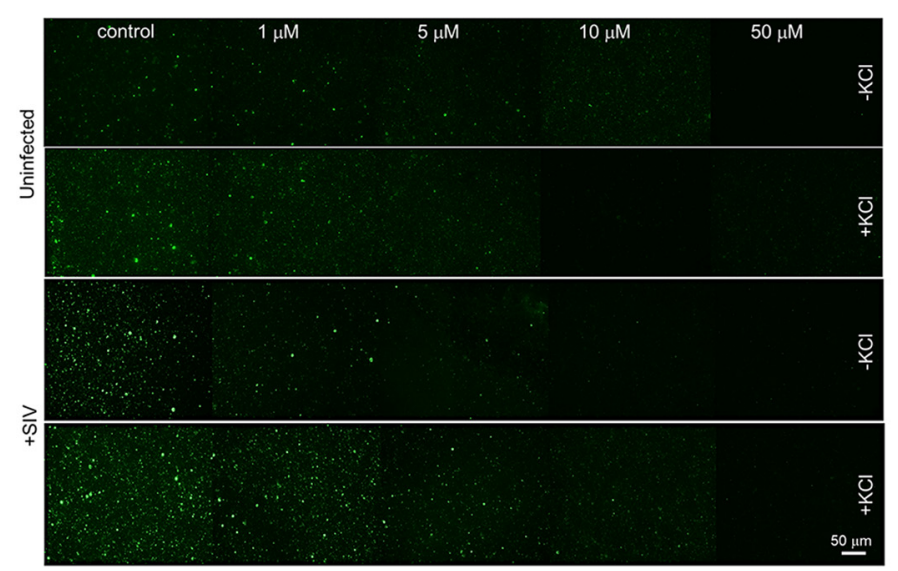

B

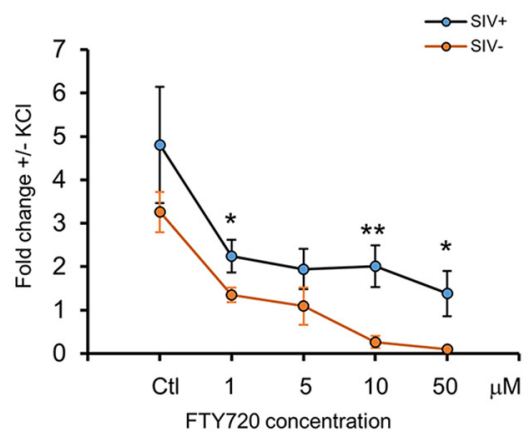

Figure 9. Treatment of synaptosomes with a phosphatase-activating drug (FTY720) mitigates SV endocytosis in frontal cortex synaptosomes of rhesus macaques. A, FTY720 was applied in different concentrations on frontal cortex synaptosomes in SVE assay in the presence of $40 \mathrm{~mm} \mathrm{KCl}$ and FM4 - 64. FTY720 produced lower fluorescence signals in a concentration-dependent fashion. In SIV ${ }^{+}$synaptosomes, higher concentrations of FTY720 were required to quench the signals. B, Quantification of fluorescence signals detected in $A$ using the ratio of the total fluorescence recorded after depolarization by $40 \mathrm{~mm} \mathrm{KCl}$ in different conditions. ${ }^{*} p<0.05$ (Student's $t$ test). ${ }^{* *} p<0.005$ (Student's $t$ test). Error bars indicate mean \pm SEM.

\section{A}

\begin{tabular}{|c|c|c|c|c|c|c|c|}
\hline 0 & 100 & 200 & 300 & 400 & 500 & 600 & 700 \\
\hline s9 & $\begin{array}{c}\mathrm{s} 62 \mathrm{~S} 67 \\
\mathbf{7}\end{array}$ & & & & & $\stackrel{\mathrm{s} 603}{7}$ & \\
\hline A & B & & C & & & & $\mathrm{E}$ \\
\hline
\end{tabular}

B

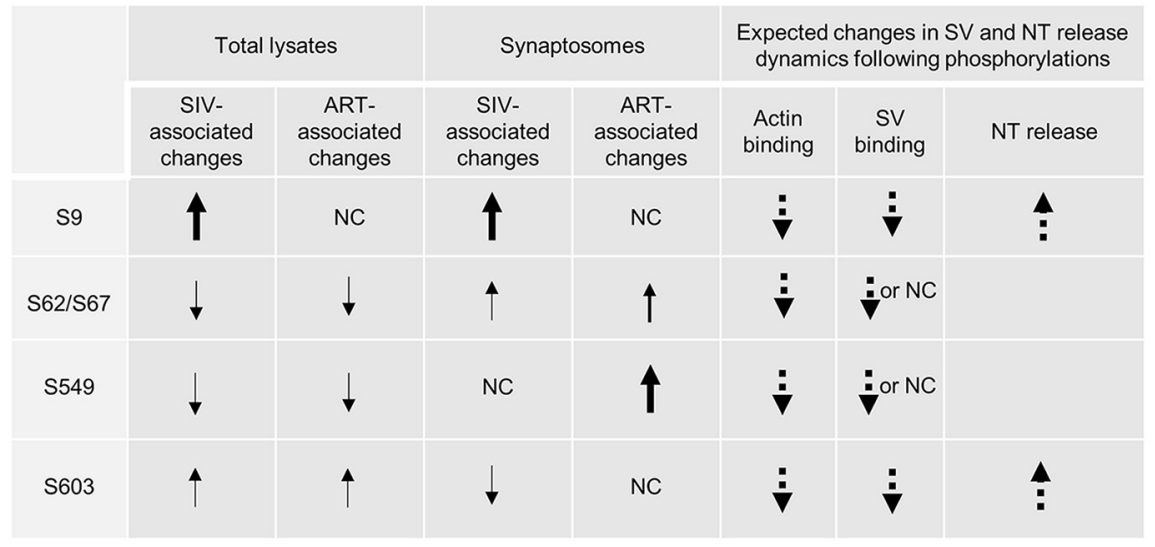

Figure 10. Dynamics of the impact of SIV infection and ART regimen on Syn I phosphorylations. $A$, Amino acid residues studied in this work and their approximate positions in the Syn I domains $(A-E)$. B, Observed changes in phosphorylations at multiple sites of Syn I in total lysates versus synaptosome preparations and functional impact of phosphorylation of these sites in normal physiological conditions based on Cesca et al. (2010). Thin arrows indicate insignificant trends. Thick arrows indicate significant changes. NC, No changes; AA, amino acids; NT, neurotransmitter.

zyme form of PP2A-inhibited Tat-induced HIV-1 transcription and PP2A indirectly enhanced HIV-1 transcription (Ruediger et al., 1997; Faulkner et al., 2003). HIV-1 viral infectivity factor was able to degrade PP2A regulatory subunits in vitro (Evans et al., 2018). Recently, Schott et al. (2018) have demonstrated that PP2A dephosphorylates SAM domain and HD domaincontaining protein 1 , a protein that inhibits HIV-1 replication in dendritic and myeloid cells, and identified PP2A as a key regulator of antiviral activity of SAM domain and HD domaincontaining protein 1 . These studies strongly suggest the role of PP2A in the HIV-1 infection and replication in infected cells, and imply pathological interactions of HIV-expressed proteins with PP2A subunits. Our current findings support a lower activity of
PP2A in neurons and provide a strong evidence that changes in PP2A activity might contribute to HIV neuropathogenesis by interfering with normal interaction of PP2A with its substrates.

HIV-1 Tat and gp120 proteins have been identified as the main candidates to elicit neurotoxic effects on the synaptic density, even before triggering chronic events, such as neuronal cell death (Sá et al., 2004; Bruce-Keller et al., 2008; Kim et al., 2008; Lu et al., 2011; Shin and Thayer, 2013; Bertrand et al., 2014; Puccini et al., 2015). Studies of HIV-1-associated neuronal impairments in HIV-1 transgenic rats and Tat transgenic mice have revealed significant changes in synaptodendritic integrity and behavioral deficits (Fitting et al., 2013; Roscoe et al., 2014; Hahn et al., 2015). For instance, both proteins have been implicated in impairing 
glutamate recycling by increasing glutamine release and reducing its uptake at the synaptic cleft (Vesce et al., 1997; Musante et al., 2010). The effect of Tat in inducing changes in the synaptic integrity and the inhibition of hippocampal synapses and network have been reported (Hargus and Thayer, 2013; Mohseni Ahooyi et al., 2018). A Tat-induced excitatory state was also proposed in the brain of Tat transgenic mice (Zucchini et al., 2013).

In addition, persistent immune response to HIV-1 infection also affects neuronal function by overproducing cytokines and chemokines. HIV-1-associated activation of macrophage and microglia, the production of proinflammatory cytokines, and subsequent detection in the CSF of PWH were correlated with HIV neurocognitive impairments (Bandaru et al., 2007). Both IL1 $\beta$ and TNF $\alpha$ downregulate the expression of excitatory amino acid transporter 2, which plays an important role in up taking of excess glutamate from the synaptic cleft (VartakSharma et al., 2014).

Our findings demonstrated that PP2A activity is impaired in the brain of SIV-infected animals, which indirectly dysregulates post-translational modification of PP2A targets. This impaired activity may be associated with the presence of SIV proteins, active infection, activation of resident immune brain cells, and/or increased proinflammatory cytokines. These experiments are currently under investigation. In an experimental autoimmune encephalomyelitis model, a mixture of proinflammatory cytokines, including Th1, TNF $\alpha$, IFN $\gamma$, and IL-1 $\beta$, induced Syn I phosphorylations by ERK1/2 pathway (Guarnieri et al., 2018). Thus, extracellular signals may modulate PP2A activity toward its substrates leading to multiple physiological impairments.

Neuronal markers, such as microtubule-associated protein 2 and the presynaptic protein, synaptophysin, are downregulated in PWH (Desplats et al., 2013). The unchanged Syn I protein expression observed in the synaptosome and lysates preparations of frontal cortex of uninfected and $\mathrm{SIV}^{+}$using Western blot analysis and previous findings in HIV-1 ${ }^{+}$human brains showing lower optical density of Syn I immunolabeling in the brain sections in the neocortical with high HIV-1 RNA load indicate a dysregulation in the Syn I protein distributions at the cellular levels. A reduction in the Syn I expression was reported in Tat transgenic mice and in vitro in a neuroblastoma cell line (Gelman and Nguyen, 2010; Hahn et al., 2015; Guha et al., 2018). These findings support the impact of several factors in the Syn I expression and post-translational modifications, which should be considered for future work. Thus, the presence of HIV-1 proteins may contribute to abnormal neuronal transmission by modulating neuronally expressed proteins.

We found a decreasing trend of Syn I (S603) phosphorylation in synaptosomes, a site dephosphorylated by PP2A, which supports a lower PP2A activity in synaptosome of $\mathrm{SIV}^{+}$animals (Jovanovic et al., 2001). However, we also reported a significant increase in CaMKII activity in the total lysates of frontal cortex from $\mathrm{SIV}^{+}$animals, which supports higher phosphorylation of Syn I (S603) in the lysates. Recent reports of changes in the CaMKII expression indicated a lower expression of total CaMKII protein when normalized with MAP2 in the frontal cortex of PWH with neurocognitive impairments and in differentiated human SH-5YSY neuroblastoma cells exposed to supernatants of HIV-1-infected macrophages (Guha et al., 2018). However, the CaMKII activity was rapidly induced in mice by intrathecal injection of HIV-1 gp120 (Li et al., 2013). In doxycycline-inducible HIV-1 Tat mice, the CaMKII activity and expression were reduced in male mice (Nookala et al., 2018). In an SIV infection model, an increase in the CaMKII expression was found in the hippocampus and frontal cortex of $\mathrm{SIV}^{+}$animals (Gupta et al., 2010). Our findings on the CaMKII expression and activity in total lysates versus synaptosome preparations suggest a dysregulation in subcellular distributions of neuronal and nonneuronally expressed CaMKII protein and its activity.

For the first time, we performed the endocytosis assay on nonhuman primate frozen brain samples using FM4-64. This allowed us to functionally test the excitability of $\mathrm{SIV}^{+}$synaptosomes and assess the differences with uninfected animals. Furthermore, we tested the potential application of an FDAapproved drug, FTY720 (fingolimod), to mitigate the synaptosome depolarization in $\mathrm{SIV}^{+}$animals by activating PP2A. We found that the application of FTY720 was sufficient to mitigate SV depolarization, which was delayed in synaptosomes of $\mathrm{SIV}^{+}$ animals. FTY720 was also shown to inhibit the cytokine production in vitro (Yu et al., 2015). Interestingly, HIV-1 transgenic rats exhibit altered inflammatory pathways and develop pulmonary hypertension (Lund et al., 2011). FTY720 also significantly represses proinflammatory cytokines (Rahman et al., 2016a,b). These findings further support the role of PP2A deficiency in SV release and provide a proof of principle for clinical intervention in PWH with neurological impairment. Together, our findings suggest a significant dysregulation in the dynamics of SV release during depolarization because of altered Syn I (S9) phosphorylation in $\mathrm{SIV}^{+}$animals conferring key pathology at the synaptic levels.

\section{References}

Angers A, Fioravante D, Chin J, Cleary LJ, Bean AJ, Byrne JH (2002) Serotonin stimulates phosphorylation of Aplysia synapsin and alters its subcellular distribution in sensory neurons. J Neurosci 22:5412-5422.

Bähler M, Benfenati F, Valtorta F, Greengard P (1990) The synapsins and the regulation of synaptic function. Bioessays 12:259-263.

Bandaru VV, McArthur JC, Sacktor N, Cutler RG, Knapp EL, Mattson MP, Haughey NJ (2007) Associative and predictive biomarkers of dementia in HIV-1-infected patients. Neurology 68:1481-1487.

Bertrand SJ, Mactutus CF, Aksenova MV, Espensen-Sturges TD, Booze RM (2014) Synaptodendritic recovery following HIV Tat exposure: neurorestoration by phytoestrogens. J Neurochem 128:140-151.

Bonanomi D, Menegon A, Miccio A, Ferrari G, Corradi A, Kao HT, Benfenati F, Valtorta F (2005) Phosphorylation of synapsin I by cAMP-dependent protein kinase controls synaptic vesicle dynamics in developing neurons. J Neurosci 25:7299-7308.

Bruce-Keller AJ, Turchan-Cholewo J, Smart EJ, Geurin T, Chauhan A, Reid R, Xu R, Nath A, Knapp PE, Hauser KF (2008) Morphine causes rapid increases in glial activation and neuronal injury in the striatum of inducible HIV-1 Tat transgenic mice. Glia 56:1414-1427.

Burdo TH, Lackner A, Williams KC (2013) Monocyte/macrophages and their role in HIV neuropathogenesis. Immunol Rev 254:102-113.

Cesca F, Baldelli P, Valtorta F, Benfenati F (2010) The synapsins: key actors of synapse function and plasticity. Prog Neurobiol 91:313-348.

Cheetham JJ, Hilfiker S, Benfenati F, Weber T, Greengard P, Czernik AJ (2001) Identification of synapsin I peptides that insert into lipid membranes. Biochem J 354:57-66.

Chi P, Greengard P, Ryan TA (2001) Synapsin dispersion and reclustering during synaptic activity. Nat Neurosci 4:1187-1193.

Chi P, Greengard P, Ryan TA (2003) Synaptic vesicle mobilization is regulated by distinct synapsin I phosphorylation pathways at different frequencies. Neuron 38:69-78.

Coffey ET, Sihra TS, Nicholls DG (1993) Protein kinase C and the regulation of glutamate exocytosis from cerebrocortical synaptosomes. J Biol Chem 268:21060-21065.

Daniel JA, Malladi CS, Kettle E, McCluskey A, Robinson PJ (2012) Analysis of synaptic vesicle endocytosis in synaptosomes by high-content screening. Nat Protoc 7:1439-1455.

Delghandi MP, Johannessen M, Moens U (2005) The cAMP signalling pathway activates CREB through PKA, p38 and MSK1 in NIH 3 T3 cells. Cell Signal 17:1343-1351. 
Desplats P, Dumaop W, Smith D, Adame A, Everall I, Letendre S, Ellis R, Cherner M, Grant I, Masliah E (2013) Molecular and pathologic insights from latent HIV-1 infection in the human brain. Neurology 80:1415-1423.

Eggers C, Arendt G, Hahn K, Husstedt IW, Maschke M, Neuen-Jacob E, Obermann M, Rosenkranz T, Schielke E, Straube E (2017) HIV-1associated neurocognitive disorder: epidemiology, pathogenesis, diagnosis, and treatment. J Neurol 264:1715-1727.

Epie N, Ammosova T, Turner W, Nekhai S (2006) Inhibition of PP2A by LIS1 increases HIV-1 gene expression. Retrovirology 3:65.

Evans EL 3rd, Becker JT, Fricke SL, Patel K, Sherer NM (2018) HIV-1 Vif's capacity to manipulate the cell cycle is species specific. J Virol 92:e2102-17.

Fassio A, Patry L, Congia S, Onofri F, Piton A, Gauthier J, Pozzi D, Messa M, Defranchi E, Fadda M, Corradi A, Baldelli P, Lapointe L, St-Onge J, Meloche C, Mottron L, Valtorta F, Khoa Nguyen D, Rouleau GA, Benfenati F, Cossette P (2011) SYN1 loss-of-function mutations in autism and partial epilepsy cause impaired synaptic function. Hum Mol Genet 20:2297-2307.

Faulkner NE, Lane BR, Bock PJ, Markovitz DM (2003) Protein phosphatase $2 \mathrm{~A}$ enhances activation of human immunodeficiency virus type 1 by phorbol myristate acetate. J Virol 77:2276-2281.

Fitting S, Ignatowska-Jankowska BM, Bull C, Skoff RP, Lichtman AH, Wise LE, Fox MA, Su J, Medina AE, Krahe TE, Knapp PE, Guido W, Hauser KF (2013) Synaptic dysfunction in the hippocampus accompanies learning and memory deficits in human immunodeficiency virus type-1 Tat transgenic mice. Biol Psychiatry 73:443-453.

Gelman BB (2015) Neuropathology of HAND with suppressive antiretroviral therapy: encephalitis and neurodegeneration reconsidered. Curr HIV/ AIDS Rep 12:272-279.

Gelman BB, Nguyen TP (2010) Synaptic proteins linked to HIV-1 infection and immunoproteasome induction: proteomic analysis of human synaptosomes. J Neuroimmune Pharmacol 5:92-102.

Greengard P, Valtorta F, Czernik AJ, Benfenati F (1993) Synaptic vesicle phosphoproteins and regulation of synaptic function. Science 259:780785.

Guarnieri FC, Bellani S, Yekhlef L, Bergamaschi A, Finardi A, Fesce R, Pozzi D, Monzani E, Fornasiero EF, Matteoli M, Martino G, Furlan R, Taverna S, Muzio L, Valtorta F (2018) Synapsin I deletion reduces neuronal damage and ameliorates clinical progression of experimental autoimmune encephalomyelitis. Brain Behav Immun 68:197-210.

Guergnon J, Godet AN, Galioot A, Falanga PB, Colle JH, Cayla X, Garcia A (2011) PP2A targeting by viral proteins: a widespread biological strategy from DNA/RNA tumor viruses to HIV-1. Biochim Biophys Acta 1812: $1498-1507$.

Guha D, Wagner MC, Ayyavoo V (2018) Human immunodeficiency virus type 1 (HIV-1)-mediated neuroinflammation dysregulates neurogranin and induces synaptodendritic injury. J Neuroinflammation 15:126.

Gupta RG, Kelly KM, Helke KL, Queen SE, Karper JM, Dorsey JL, Brice AK, Adams RJ, Tarwater PM, Kolson DL, Mankowski JL (2010) HIV and SIV induce alterations in CNS CaMKII expression and activation: a potential mechanism for cognitive impairment. J Pathol 176:2776-2784.

Hahn YK, Podhaizer EM, Farris SP, Miles MF, Hauser KF, Knapp PE (2015) Effects of chronic HIV-1 Tat exposure in the CNS: heightened vulnerability of males versus females to changes in cell numbers, synaptic integrity, and behavior. Brain Struct Funct 220:605-623.

Hargus NJ, Thayer SA (2013) Human immunodeficiency virus-1 Tat protein increases the number of inhibitory synapses between hippocampal neurons in culture. J Neurosci 33:17908-17920.

Haughey NJ, Nath A, Mattson MP, Slevin JT, Geiger JD (2001) HIV-1 Tat through phosphorylation of NMDA receptors potentiates glutamate excitotoxicity. J Neurochem 78:457-467.

Hosaka M, Südhof TC (1999) Homo- and heterodimerization of synapsins. J Biol Chem 274:16747-16753.

Huttner WB, DeGennaro LJ, Greengard P (1981) Differential phosphorylation of multiple sites in purified protein I by cyclic AMP-dependent and calcium-dependent protein kinases. J Biol Chem 256:1482-1488.

Jovanovic JN, Benfenati F, Siow YL, Sihra TS, Sanghera JS, Pelech SL, Greengard P, Czernik AJ (1996) Neurotrophins stimulate phosphorylation of synapsin I by MAP kinase and regulate synapsin I-actin interactions. Proc Natl Acad Sci U S A 93:3679-3683.

Jovanovic JN, Sihra TS, Nairn AC, Hemmings HC Jr, Greengard P, Czernik AJ
(2001) Opposing changes in phosphorylation of specific sites in synapsin I during $\mathrm{Ca}^{2+}$-dependent glutamate release in isolated nerve terminals. J Neurosci 21:7944-7953.

Kim HJ, Martemyanov KA, Thayer SA (2008) Human immunodeficiency virus protein Tat induces synapse loss via a reversible process that is distinct from cell death. J Neurosci 28:12604-12613.

Lachman HM, Stopkova P, Papolos DF, Pedrosa E, Margolis B, Aghalar MR, Saito T (2006) Analysis of synapsin III-196 promoter mutation in schizophrenia and bipolar disorder. Neuropsychobiology 53:57-62.

Lakritz JR, Robinson JA, Polydefkis MJ, Miller AD, Burdo TH (2015) Loss of intraepidermal nerve fiber density during SIV peripheral neuropathy is mediated by monocyte activation and elevated monocyte chemotactic proteins. J Neuroinflammation 12:237

Li B, Shi Y, Shu J, Gao J, Wu P, Tang SJ (2013) Wingless-type mammary tumor virus integration site family, member $5 \mathrm{~A}$ (Wnt5a) regulates human immunodeficiency virus type 1 (HIV-1) envelope glycoprotein 120 (gp120)-induced expression of pro-inflammatory cytokines via the $\mathrm{Ca}^{2+} /$ calmodulin-dependent protein kinase II (CaMKII) and c-jun $\mathrm{N}$-terminal kinase (JNK) signaling pathways. J Biol Chem 288: $13610-13619$.

Lignani G, Raimondi A, Ferrea E, Rocchi A, Paonessa F, Cesca F, Orlando M, Tkatch T, Valtorta F, Cossette P, Baldelli P, Benfenati F (2013) Epileptogenic Q555X SYN1 mutant triggers imbalances in release dynamics and short-term plasticity. Hum Mol Genet 22:2186-2199.

Liguori M, Cittadella R, Manna I, Valentino P, La Russa A, Serra P, Trojano M, Messina D, Ruscica F, Andreoli V, Romeo N, Livrea P, Quattrone A (2004) Association between synapsin III gene promoter polymorphisms and multiple sclerosis. J Neurol 251:165-170.

Lou X (2018) Sensing exocytosis and triggering endocytosis at synapses: synaptic vesicle exocytosis-endocytosis coupling. Front Cell Neurosci 12: 66.

Lu SM, Tremblay MÈ, King IL, Qi J, Reynolds HM, Marker DF, Varrone JJ, Majewska AK, Dewhurst S, Gelbard HA (2011) HIV-1 Tat-induced microgliosis and synaptic damage via interactions between peripheral and central myeloid cells. PLoS One 6:e23915.

Lund AK, Lucero J, Herbert L, Liu Y, Naik JS (2011) Human immunodeficiency virus transgenic rats exhibit pulmonary hypertension. Am J Physiol Lung Cell Mol Physiol 301:L315-L326.

Macia E, Ehrlich M, Massol R, Boucrot E, Brunner C, Kirchhausen T (2006) Dynasore, a cell-permeable inhibitor of dynamin. Dev Cell 10:839-850.

McAvoy T, Nairn AC (2010) Serine/threonine protein phosphatase assays. Curr Protoc Mol Biol Chapter 18, Unit 18:18.

Menegon A, Bonanomi D, Albertinazzi C, Lotti F, Ferrari G, Kao HT, Benfenati F, Baldelli P, Valtorta F (2006) Protein kinase A-mediated synapsin I phosphorylation is a central modulator of $\mathrm{Ca}^{2+}$-dependent synaptic activity. J Neurosci 26:11670-11681.

Menegon A, Dunlap DD, Castano F, Benfenati F, Czernik AJ, Greengard P, Valtorta F (2000) Use of phosphosynapsin I-specific antibodies for image analysis of signal transduction in single nerve terminals. J Cell Sci 113:3573-3582.

Mohseni Ahooyi T, Shekarabi M, Decoppet EA, Langford D, Khalili K, Gordon J (2018) Network analysis of hippocampal neurons by microelectrode array in the presence of HIV-1 Tat and cocaine. J Cell Physiol 233:9299-9311.

Musante V, Summa M, Neri E, Puliti A, Godowicz TT, Severi P, Battaglia G, Raiteri M, Pittaluga A (2010) The HIV-1 viral protein Tat increases glutamate and decreases GABA exocytosis from human and mouse neocortical nerve endings. Cereb Cortex 20:1974-1984.

Nookala AR, Schwartz DC, Chaudhari NS, Glazyrin A, Stephens EB, Berman NEJ, Kumar A (2018) Methamphetamine augment HIV-1 Tat mediated memory deficits by altering the expression of synaptic proteins and neurotrophic factors. Brain Behav Immun 71:37-51.

Onofri F, Giovedì S, Vaccaro P, Czernik AJ, Valtorta F, De Camilli P, Greengard P, Benfenati F (1997) Synapsin I interacts with c-src and stimulates its tyrosine kinase activity. Proc Natl Acad Sci U S A 94:12168-12173.

Perrotti D, Neviani P (2013) Protein phosphatase 2A: a target for anticancer therapy. Lancet Oncol 14:e229-e238.

Puccini JM, Marker DF, Fitzgerald T, Barbieri J, Kim CS, Miller-Rhodes P, Lu SM, Dewhurst S, Gelbard HA (2015) Leucine-rich repeat kinase 2 modulates neuroinflammation and neurotoxicity in models of human immunodeficiency virus 1-associated neurocognitive disorders. J Neurosci 35: $5271-5283$ 
Rahman MM, Prünte L, Lebender LF, Patel BS, Gelissen I, Hansbro PM, Morris JC, Clark AR, Verrills NM, Ammit AJ (2016a) The phosphorylated form of FTY720 activates PP2A represses inflammation and is devoid of S1P agonism in A549 lung epithelial cells. Sci Rep 6:37297.

Rahman MM, Rumzhum NN, Hansbro PM, Morris JC, Clark AR, Verrills NM, Ammit AJ (2016b) Activating protein phosphatase 2A (PP2A) enhances tristetraprolin (TTP) anti-inflammatory function in A549 lung epithelial cells. Cell Signal 28:325-334.

Roscoe RF Jr, Mactutus CF, Booze RM (2014) HIV-1 transgenic female rat: synaptodendritic alterations of medium spiny neurons in the nucleus accumbens. J Neuroimmune Pharmacol 9:642-653.

Ruediger R, Brewis N, Ohst K, Walter G (1997) Increasing the ratio of PP2A core enzyme to holoenzyme inhibits Tat-stimulated HIV-1 transcription and virus production. Virology 238:432-443.

Sá MJ, Madeira MD, Ruela C, Volk B, Mota-Miranda A, Paula-Barbosa MM (2004) Dendritic changes in the hippocampal formation of AIDS patients: a quantitative Golgi study. Acta Neuropathol 107:97-110.

Saviouk V, Moreau MP, Tereshchenko IV, Brzustowicz LM (2007) Association of synapsin 2 with schizophrenia in families of Northern European ancestry. Schizophr Res 96:100-111.

Schott K, Fuchs NV, Derua R, Mahboubi B, Schnellbächer E, Seifried J, Tondera C, Schmitz H, Shepard C, Brandariz-Nuñez A, Diaz-Griffero F, Reuter A, Kim B, Janssens V, König R (2018) Dephosphorylation of the HIV-1 restriction factor SAMHD1 is mediated by PP2A-B55alpha holoenzymes during mitotic exit. Nat Commun 9:2227.

Shin AH, Thayer SA (2013) Human immunodeficiency virus-1 protein Tat induces excitotoxic loss of presynaptic terminals in hippocampal cultures. Mol Cell Neurosci 54:22-29.

Südhof TC (2012) The presynaptic active zone. Neuron 75:11-25.

Swingle M, Ni L, Honkanen RE (2007) Small-molecule inhibitors of Ser/ Thr protein phosphatases: specificity, use and common forms of abuse. Methods Mol Biol 365:23-38.

Tang LT, Craig TJ, Henley JM (2015) SUMOylation of synapsin Ia maintains synaptic vesicle availability and is reduced in an autism mutation. Nat Commun 6:7728.

Vartak-Sharma N, Gelman BB, Joshi C, Borgamann K, Ghorpade A (2014) Astrocyte elevated gene-1 is a novel modulator of HIV-1-associated neuroin- flammation via regulation of nuclear factor-kappaB signaling and excitatory amino acid transporter-2 repression. J Biol Chem 289:19599-19612.

Vesce S, Bezzi P, Rossi D, Meldolesi J, Volterra A (1997) HIV-1 gp120 glycoprotein affects the astrocyte control of extracellular glutamate by both inhibiting the uptake and stimulating the release of the amino acid. FEBS Lett 411:107-109.

Wayman GA, Impey S, Marks D, Saneyoshi T, Grant WF, Derkach V, Soderling TR (2006) Activity-dependent dendritic arborization mediated by CaM-kinase I activation and enhanced CREB-dependent transcription of Wnt-2. Neuron 50:897-909.

Xu Q, Huang S, Song M, Wang CE, Yan S, Liu X, Gaertig MA, Yu SP, Li H, Li S, Li XJ (2013) Synaptic mutant huntingtin inhibits synapsin-1 phosphorylation and causes neurological symptoms. J Cell Biol 202:11231138.

Yadav VK, Oury F, Suda N, Liu ZW, Gao XB, Confavreux C, Klemenhagen KC, Tanaka KF, Gingrich JA, Guo XE, Tecott LH, Mann JJ, Hen R, Horvath TL, Karsenty G (2009) A serotonin-dependent mechanism explains the leptin regulation of bone mass, appetite, and energy expenditure. Cell 138:976-989.

Yamada H, Padilla-Parra S, Park SJ, Itoh T, Chaineau M, Monaldi I, Cremona O, Benfenati F, De Camilli P, Coppey-Moisan M, Tramier M, Galli T, Takei K (2009) Dynamic interaction of amphiphysin with N-WASP regulates actin assembly. J Biol Chem 284:34244-34256.

Yu H, Herbert BA, Valerio M, Yarborough L, Hsu LC, Argraves KM (2015) FTY720 inhibited proinflammatory cytokine release and osteoclastogenesis induced by Aggregatibacter actinomycetemcomitans. Lipids Health Dis 14:66.

Zhou J, Pham HT, Ruediger R, Walter G (2003) Characterization of the Aalpha and Abeta subunit isoforms of protein phosphatase 2A: differences in expression, subunit interaction, and evolution. Biochem J 369:387-398.

Zucchini S, Pittaluga A, Brocca-Cofano E, Summa M, Fabris M, De Michele R, Bonaccorsi A, Busatto G, Barbanti-Brodano G, Altavilla G, Verlengia G, Cifelli P, Corallini A, Caputo A, Simonato M (2013) Increased excitability in Tat-transgenic mice: role of Tat in HIV-related neurological disorders. Neurobiol Dis 55:110-119. 